\title{
Editorial
}

\section{Maternal, adolescent and child health issues in low and middle income countries: towards achieving the sustainable development goals}

\author{
Grace Ndeezi
}

College of Health Sciences, Makerere University.

DOI: https://dx.doi.org/10.4314/ahs.v19i2.1

Cite as: Ndeezi G. Maternal, adolescent and child health issues in low and middle income countries: towards achieving the sustainable development goals. Afri Health Sci.2019;19(2): I-III. bttps:/ / dx.doi.org/10.4314/abs.v19i2.1

This editorial covers the maternal, child and adolescent health papers published in the June 2019 issue of African Health Sciences.

\section{Maternal Health}

In this issue we bring you an interesting paper on precclampsia from South Africa. Pre-eclampsia is one of the main causes of maternal and perinatal morbidity and mortality whose pathogenesis and pathophysiology is poorly understood. In their paper, Ogunlola et al ${ }^{1}$ quantitatively analysed serum samples for angiogenic factors through 10 to 38 weeks of gestation in uncomplicated pregnancy in Durnan, South Africa. In these women angiogenic and anti-angiogenic levels were fluctuating and none had pre-eclampsia. Although increase in anti-angiogenic factors have been associated with widespread endothelial dysfunction, affecting all the maternal organ systems leading to pre-eclampsia, fluctuation of these factors in pregnancy may be a normal phenomenon and cut off levels for pre-eclampsia should be established.

The role of training in emergency obstetric care (EMOC) in low and middle income countries and how it influences maternal outcomes is of major interest. A study by Nkhwalume et al in Botswana showed no reduction in maternal mortality before and after training in emergency obstetric care. ${ }^{2}$ This is very surprising since it is well known that provision of quality emergency obstetric care improves maternal and neonatal outcomes. Other than training there are other factors that may influence practice. Further studies using a qualitative approach are needed to find out why training in EMOC may not improve maternal mortality.

This issue also publishes a study from Western Kenyathat evaluated the introduction of a voluntary family health insurance program with quality improvement of health care facilities and the introduction of free access to delivery services in all public facilities. Slightly over $50 \%$ of the women used modern family planning methods and a similar number attended the 4 minimum recommended antenatal care visits. ${ }^{3}$ From South Africa we have an interesting paper on intimate partner violence. It"uncovered discourses that may help understand emergency nurses' responses towards women exposed to intimate partner violence". ${ }^{4}$ Rubella and syphilis are still common causes of congenital infections in Tanzania; and this warrants strengthening of testing and preventive services in pregnancy. ${ }^{5}$

Despite improved access to contraceptives, antibiotics and promotion of safe abortion practices a study, in Lagos Nigeria, showed that more than a third of infertile women had tubal pathologies and this remains the most common abnormality seen on hysterosapingograms. ${ }^{6}$ Also from Nigeria, we have a paper on the attitude of married women towards contraceptive use in Kwara State. Many married women had negative attitudes to- 
wards contraceptive use, irrespective of age and level of education. $^{7}$

This issue of African Health Sciencesalso publishes an interesting topic that has not been well studied in LMICs: sexual functions of women before and after menopause. Using the Female Sexual Function index among women in Turkey, Yagmur et al report that more than $50 \%$ of women had sexual dysfunction and the risk factors were low education level, poorincome and menopausal status. ${ }^{8}$

\section{Adolescent health}

A study from an adolescent clinic in Uganda's national referral hospital in Kampala showed that 'poor quality of home life and chronic illness were associated with depression while substance abuse correlated with maternal death, substance use among family members and friends. ${ }^{9}$ There is need for 'comprehensive adolescent care services' to address 'the psychosocial issues and the home environment.'

\section{Child health}

Child malnutrition remains a public health problem and a major contributor to child morbidity and mortality in LMICs. In a study by Yirga et al based on the demographic and health survey results of 2016, under five nutritional status in Ethiopia was associated with the child's age, birth weight, sex, mother's age, mother's body mass index and marital status. ${ }^{10}$

We also publish the findings of a study at a University Teaching Hospital in Nigeria where $60 \%$ of paediatric admissions were during "off-hours. About a quarter of the admissions were due to fever, sickle cell anaemia and sepsis. The two later conditions were associated with prolonged hospital stay. ${ }^{11}$ Common causes of morbidity such as fever contributed the highest percentage of admissions.

Another paper addresses determinants of adverse neonatal outcomes among post-natal women in Dar es Salaam, Tanzania. The authors report that 'gestational age and malaria were significantly associated with adverse neonatal outcomes'. ${ }^{2}$ In a study from Ethiopia the risk factors for still births were maternal hypertension, low birth weight, prematurity, alcohol intake, polyhydramnios and meconium stained amniotic fluid. ${ }^{13}$
Despite the progress during the Millennium Development Goals major challenges remain in terms of reducing maternal and child mortality, improving nutrition and achieving progress against infectious diseases. Programmes that address the Sustainable Development Goals should remain the priority.

\section{References}

1. Ogunlola M, Reddy P, Sibiya NM, O'Connor L, Borg D, Haffejee F, Ghuman S, Ngxongo T, Govender N. Circulating soluble fms-like tyrosine kinase-1, soluble endoglin and placental growth factor during pregnancy in normotensive women in KwaZulu-Natal, South Africa. Afri Health Sci. 2019;19(2). 1821-1832. https://dx.doi. org/10.4314/ahs.v19i2.4

2. Nkhwalume L, Mashalla Y. Maternal mortality trends at the Princess Marina and Nyangabwereferral hospitals in Botswana. Afri Health Sci. 2019;19(2). 1833-1840. https://dx.doi.org/10.4314/ahs.v19i2.5

3. Mwangi A, Nangami M, Tabu J, Ayuku D, Were E, Fabian E. A system approach to improving maternal and child health care delivery in Kenyan communities and primary care facilities: baseline survey on maternal health. Afri Health Sci. 2019;19(2). 1841-1848. https://dx.doi. org/10.4314/ahs.v19i2.6

4. van der Wath A. Women exposed to intimate partner violence: A Foucauldian discourse analysis of South African emergency nurses' perceptions. Afri Health Sci. 2019: 19(2). 1849-1857. https://dx.doi.org/10.4314/ahs. v19i2.7

5. Mirambo MM, Mshana ES, Gro $\beta$ U. Rubella virus, Toxoplasma gondiiand Treponema pallidum congenital infections among full term delivered women in an urban area of Tanzania: a call for improved antenatal care. Afri Health Sci. 2019;19(2). 1858-1865. https://dx.doi. org/10.4314/ahs.v19i2.8

6. Omidiji ATO, Toyobo OO, Adegbola O, Fatade A,Olowoyeye AO. Hysterosalpingographic findings in infertility - what has changed over the years? Afri Health Sci. 2019;19(2). 1866-1874. https://dx.doi.org/10.4314/ ahs.v19i2.9

7. Adegboyega LO. Attitude of married women towards contraceptive use in Ilorin Metropolis, Kwara State, Nigeria. Afri Health Sci. 2019;19(2). 1875-1880. https://dx. doi.org/10.4314/ahs.v19i2.10

8. Yağmur Y, Orhan I. Examining sexual functions of 
women before and after menopause. Afri Health Sci. 2019;19(2). 1881-1887. https://dx.doi.org/10.4314/ahs. v19i2.11

9. Henry BM, Bakeera-Kitaka S, Lubega K, Snyder AS, LaRussa P, Pfeffer B. Depressive symptoms, sexual activity, and substance use among adolescents in Kampala, Uganda. Afri Health Sci. 2019;19(2). 1888-1896. https:// dx.doi.org/10.4314/ahs.v19i2.12

10. YirgaAA, Mwambi GH, Ayele GD, Melesse FS. Factors affecting child malnutrition in Ethiopia. Afri Health Sci. 2019;19(2). 1897-1909. https://dx.doi.org/10.4314/ ahs.v19i2.13

11. Enyuma OAC, Anah UM, Pousson A, Olorunfemi G, Ibisomi L, Abang B E, Imoke EJ. Patterns of paediatric emergency admissions and predictors of prolonged hospital stay at the children emergency room, University of Calabar Teaching Hospital, Calabar, Nigeria. Afri Health Sci. 2019;19(2). 1910-1923. https://dx.doi.org/10.4314/ ahs.v19i2.14

12. Gwelo SA, Mbishi VJ. Determinants of adverse neonatal outcomes among postnatal women in Dar es Salaam -Tanzania. Afri Health Sci. 2019;19(2). 1924-1929. https://dx.doi.org/10.4314/ahs.v19i2.15

13. Tasew H, Zemicheal M, Teklay G, Mariye T. Risk factors of stillbirth among mothers delivered in public hospitals of Central Zone,Tigray, Ethiopia. Afri Health Sci. 2019;19(2). 1930-1937. https://dx.doi.org/10.4314/ahs. v19i2.16 